University of Louisville

ThinkIR: The University of Louisville's Institutional Repository

$12-2012$

\title{
Does inconsistent-handedness lead to a better memory or does a better memory lead to inconsistent-handedness?
}

\author{
Emily K. Carris \\ University of Louisville
}

Follow this and additional works at: https://ir.library.louisville.edu/honors

Part of the Psychology Commons

\section{Recommended Citation}

Carris, Emily K., "Does inconsistent-handedness lead to a better memory or does a better memory lead to inconsistent-handedness?" (2012). College of Arts \& Sciences Senior Honors Theses. Paper 2.

http://doi.org/10.18297/honors/2

This Senior Honors Thesis is brought to you for free and open access by the College of Arts \& Sciences at ThinkIR: The University of Louisville's Institutional Repository. It has been accepted for inclusion in College of Arts \& Sciences Senior Honors Theses by an authorized administrator of ThinkIR: The University of Louisville's Institutional Repository. This title appears here courtesy of the author, who has retained all other copyrights. For more information, please contact thinkir@louisville.edu. 
Does inconsistent-handedness lead to a better memory or does a better memory lead to inconsistent-handedness?

By

\section{Emily K. Carris}

Submitted in partial fulfillment of the requirements

for Graduation (summa or magna) cum laude and

for Graduation with Honors from the Department of Psychology (if pertinent)

University of Louisville

December, 2012 


\begin{abstract}
The purpose of the study is measure the effect of handedness and hand use on memory for how specific tasks were performed. The hypothesis of the present study is that inconsistenthanders will have better memory than consistent-handers for the hand or hands they used to perform tasks. Data analysis was preformed on 30 inconsistent-handers and 45 consistenthanders, as classified by the modified Edinburg Handedness Inventory. Tasks were performed in five different hand-use conditions: always left, usually left, no preference, usually right, and always right. The results were that both consistency of handedness and hand use had an effect on memory. The implication is that inconsistent-handers may be classified as such because they are better at remembering how they performed tasks to begin with.
\end{abstract}


Does inconsistent-handedness lead to a better memory or does a better memory lead to inconsistent-handedness?

Most people can identify the hand they use to perform different actions in their everyday life. Oldfield (1971) developed a questionnaire called the Edinburgh Handedness Inventory (EHI) to measure the consistency of handedness. For example, one of the items is comb hair and the possible responses are always left, usually left, no preference, usually right and always right. Based on their questionnaire responses, people can be classified into two different categories: inconsistent-handed or consistent-handed. Individuals are defined as inconsistent-handers if they use both of their hands to perform different actions. If individuals use either their left or right hand consistently for each action, then they are classified as consistent-handers. Previous research has suggested that inconsistent-handers have better memory than consistent-handers on various tasks. Inconsistent-handers performed better with associative recognition, where participants studied a list of word pairs and were then tested on whether the pair was intact or rearranged (Lyle, Hanaver-Torrez, Hackländer, \& Edlin, 2012) along with paired associate recall, where participants were tested on their ability to recall word pairs when given one word of the pair. Inconsistent-handers also performed better with source memory, where participants were tested on their ability to remember the source of the word whether it was heard or read (Lyle, McCabe, \& Roediger, 2008). Inconsistent-handers were also found to have fewer false memories (Lyle \& Jacobs, 2010; Lyle, Logan \& Roediger, 2008). All of these findings were based on participants being classified by the modified EHI, which is an updated version of Oldfield’s original questionnaire.

One idea that helps explain these findings is that interhemispheric interaction is greater among inconsistent-handers than among consistent-handers (Christman, Propper, \& Dion, 2004; 
Parker \& Dagnall, 2010; Propper \& Christman, 2004; Propper, Christman \& Phaneuf, 2005). Interhemispheric interaction can be defined as the two hemispheres of the brain working together through the corpus callosum. The corpus callosum is the primary part of the brain that connects the two hemispheres. Information from one hemisphere is transferred to the other through the corpus callosum. As stated earlier, inconsistent-handers use both of their hands to perform different actions, so communication between the two hemispheres may be greater than in consistent-handers. Some research has found that inconsistent-handers had a larger corpus callosum in some regions in comparison to consistent-handers (Cowell, Kertesz, \& Denenberg, 1993; Habib, Gayraud, Oliva, Regis, Salamon and Khalil, 1991; Witelson, 1985). Increased interaction may help inconsistent-handers remember more. Lyle, McCabe et al. (2008) looked at the memory deficits for split-brain patients. Split-brain patients are patients who have had their corpus callosum cut so they do not have any interaction between the two hemispheres. Lyle, McCabe et al. (2008) found that split-brain patients had trouble with free recall memory tests, where patients were to recall information about specific things with little help from cues. The evidence presented by Lyle, McCabe et al. (2008) supports the theory that interhemispheric interaction has an effect on certain memory tests.

All studies that suggest that inconsistent-handers have superior memory compared to consistent-handers assume that better memory is due to some characteristic of inconsistenthanders, such as greater interhemispheric interaction. However, it is possible that the reverse is true: the classification of an individual as an inconsistent-hander could result from the individual having a better memory. Individuals may have a better memory, and therefore remember the hand or hands they use to perform the actions listed on the EHI. Hypothetically, individuals classified as consistent-handers could, in fact, make use of both hands in daily life, but not 
remember how they have used their hands, instead assuming they used their dominant hand. This study explored the possibility that inconsistent-handers have better memory for how they have used their hands to perform actions, just as they have better memory in other domains.

This study manipulated the hand or hands that individuals use to perform different actions (this factor is hereafter called hand use, in contrast to handedness), and tested individuals’ memory for how they performed the actions, in order to determine how hand use may affect memory. Individuals may have a preference for which hand they typically perform actions. According to the original assumption, individuals that are classified as consistent-handed use either their left or their right hand consistently when performing different actions. Therefore, consistent-handers may remember things more if performed by the dominant hand that they used consistently. On the contrary, inconsistent-handers should not have a problem remembering the different hand used since they do not necessarily have a dominant hand. All of the research suggests that hand use can affect memory based on the assumption that the EHI scores correctly reflect how people use their hands in their everyday life. If the current study supports that inconsistent-handers have a better memory in every aspect then it will imply that someone may be classified as an inconsistent-hander because of his or her better memory.

It is important to explore the possibility that the EHI may not reflect individuals’ actual hand use so much as it reflects their memory for their hand use. If the current study supports this possibility, new explanations for the previously reported relationship between handedness and memory may need to be considered. All previous studies have looked at a subject's handedness and then tested the subject's memory on different activities. These studies assume that, because individuals are inconsistent-handed, they may have a better memory. However, the classification of inconsistency could itself be a result of superior memory. If memory is not affected by 
handedness, then another factor might be causing the difference in memory between consistenthanders and inconsistent-handers. One previous study by Lyle and Orsborn (2011) found that, while interhemispheric interaction may be one factor that supports better memory in inconsistent-handers, it might not be the only factor. Having a better memory may allow people to remember more accurately what hand they use to perform particular actions, which would leave open the question of what is going on to grant them superior memory in the first place.

\section{Method}

\section{Participants}

One hundred ten undergraduates participated in this experiment. Thirty-five participants did not perform every action as instructed, with some participants only performing half of the actions or not performing the actions towards the end of the experiment and these participants were excluded. Seventy-five participants were included in the analyses reported below (16 males, 58 females and one who did not specify). Thirty participants were classified as inconsistent-handers and 45 were classified as consistent-handers (method of classification given below). All participants were students in psychology classes at the University of Louisville. Compensation for participation was course credit.

\section{Materials}

The modified EHI lists ten actions, such as writing, drawing, and open jars, and participants indicated which hand they used to perform the actions: always left, usually left, no preference, usually right, and always right. Each response option has a score associated with it ranging from -10 to 10 (always left: -10; usually left: -5; no preference: 0; usually right: 5; always right: 10). Participants were classified as inconsistently handed if they scored between 75 and 75 and consistently handed if they scored -80 and below or 80 and higher. A list of 20 
actions was created. Ten of the actions involved one or more objects and ten did not. The objects were collected in a yellow bucket. There objects were a tape dispenser, a hole puncher, a piece of paper, a card, a box, four coins, a marker, a ball, a computer mouse, a Tupperware container, and two dice. The actions are listed in Appendix A. A memory test was created consisting of the 20 actions that were performed. A description of each task appeared on the test (e.g. knock on the desk) along with the response options always left, usually left, equally left and right, usually right and always right. Participants indicated their response by pressing keys on a keyboard with numbers 1-5. Always left corresponded with 1, usually left corresponded with 2, equally left and right corresponded with 3, usually right corresponded with 4 and always left corresponded with 5. The test was formatted similarly to the modified EHI.

Procedure

Up to three participants participated in the experiment at a time. Participants first gave informed consent. Then, participants completed the modified EHI on the computer and specified their sex and age. Participants then received instructions for the first phase of the experiment: the performance phase. They were told that each action would be performed with a specific hand and that they must perform the action, whether with an object or not, with this hand. The participants were then told that they would answer questions about the actions later, but not specifically a memory test. They were also told that they would rate each action on two scales. The first scale measured the difficulty of performing the action from 1 to 9 , with 1 meaning difficult and 9 meaning not difficult. The second scale measured how natural it felt to perform each action. The scale was also 1 to 9, with 1 meaning unnatural and 9 meaning natural. Participants then were instructed on the computer to perform 20 actions, four times each and each with a specified hand. An equal number of participants performed each action in each of 
five conditions: always left, usually left, equally left and right, usually right and always right. In the always left condition, participants performed an action four times with their left hand. The always right condition was similar to the always left condition except participants performed the actions with their right hand. In the usually left condition, participants performed an action three times with their left hand and once with their right hand. In the usually right condition, participants performed an action three times with their right hand and once with their left hand. In the equally left and right condition, participants performed an action twice with their left hand and twice with their right hand. Hence, each action was performed a total of four times. The two rating scales followed performance of each action. After all participants finished performing actions, instructions for a memory test were given. The instructions stated that the participants were going to be tested on their memory for how they performed the actions in the study. For each action, participants pressed a key on a computer keyboard to respond always left, usually left, equally left and right, usually right, or always right. They took the test, were debriefed, and were dismissed.

As mentioned earlier, there were some participants who did not fully follow all of the instructions given. Towards the end of the study, the experimenter stayed in the room as the subjects performed the actions, to ensure that all of the instructions were being followed.

There were five within-subject conditions for this experiment: always left, usually left, equally left and right, usually right and always right. Across participants, each action was performed in all five conditions. Actions were performed in pseudo-random order with the restriction that the same action was never repeated right after itself.

\section{Design}


There were two independent variables: 1) participant’s handedness (inconsistent or consistent), and 2) hand use for a given action (always left, usually left, equally left and right, usually right and always right). The first variable was between-subjects and the second was within-subjects. The dependent variable was the number of correct responses in each hand use condition.

\section{Results}

A 2 X 5 ANOVA was conducted and a main effect of hand use was revealed, $F(4,292)=$ $9.121, p<.001$. The always right condition yielded the most correct answers with usually right having the next best accuracy. The equally left and right condition had better accuracy than the usually left condition and the always left condition. These data suggests that hand use affected participants' memory. There was also a main effect of consistency, $F(1,73)=5.913, p=.017$. Inconsistent-handers had better memory than consistent-handers. This supports the previous research that inconsistent-handers performed better on memory tests than consistent-handers. There was no interaction between hand use and consistency, $F(4,292)=1.302, p=.269$.

As described above, memory differences were found between the always left and always right conditions, as well as between the usually right and usually left conditions. A paired $t$ test was performed to compare the always left and always right conditions. The difference was significant, $t(74)=-4.791, p<.001$. Participants remembered the actions performed in the always right condition better compared to the always left condition. A paired $t$ test was also performed to compare the usually left and usually right condition and the difference was also found to be significant, $t(74)=-3.905, p<.001$. Participants in the usually right condition performed better on the memory task compared to the usually left condition. See table 1 for the means of hand use. 


\section{Discussion}

Overall, the findings of this study raise questions about previous assumptions made in handedness research. Researchers have previously suggested that because individuals are inconsistent-handed, they have a better memory. The superior memory of inconsistent-handers has been shown through the research previously cited and the claim has been that superior memory is the result of greater interhemispheric interaction. The present study introduces evidence that may challenge some of the assumptions of the previous evidence found on inconsistent-handers and their memory.

The results indicate that hand use can have an effect on memory for how tasks are performed. More specifically, participants performed better in the always right and usually right conditions than in the other three conditions, regardless of consistency. These findings are interesting because they give insight into what can influence a person’s memory.

One possibility for explaining these findings is that people who are classified as inconsistent-handed have a better memory than those classified as consistent-handed. These inconsistent-handers may simply remember more precisely what they do with their hands than do consistent-handers. If this is the case, it poses questions about whether the EHI should be used when trying to find links between handedness and memory. The possibility that people classified as inconsistent-handers may not actually be inconsistent-handed, but rather only appear so, presents concerns to those who have based all of their conclusions about the relationship between handedness and memory on the EHI.

Regarding the effect of hand use on memory, it could be that consistently using the right hand to perform these actions may have an effect on remembering which hand was used to perform the actions. A reason for this effect on memory could be that the majority of objects are 
made for a right-handed person, such as scissors or the gearshift in a car. Participants could be familiar with using their right hand for different actions, which could increase their memory on these actions. Future experiments could explore this possible explanation by having participants perform actions in a specific condition depending on their handedness. If participants are consistently left-handed and performs actions with their right hand, then the participants' memory may be affected. This could possibly find evidence to support the suggestion that familiarity with right-handed actions can increase a person's memory on the action.

In sum, the results from this experiment raise questions about the causal relationship between handedness and memory. Previous research has suggested that inconsistent-handers have a better memory as a result of their increased interhemispheric interaction compared to consistent-handers. However, the findings of this study raise the possibility that the EHI may not be correctly classifying individuals as inconsistent or consistent in the first place. This could lead to the development of another form of classification for handedness and further research should be conducted to look at other ways to test consistency. 


\section{References}

Christman, S.D., Propper, R.E., \& Dion, A. (2004). Increased interhemispheric interaction is associated with decreased false memories in a verbal converging semantic associates paradigm. Brain and Cognition, 56, 313-319.

Cowell, P. E., Kertesz, A., \& Denenberg, V. H. (1993). Multiple dimensions of handedness and the human corpus callosum. Neurology, 43, 2353-2357.

Habib, M., Gayraud, D., Oliva, A., Regis, J., Salamon G. and Khalil R. (1991). Effects of handedness and sex on the morphology of the corpus callosum: a study with brain magnetic resonance imaging. Brain and Cognition, 16, 41-61.

Lyle, K.B., Hanaver-Torrez, S.D., Hackländer, R.P., \& Edlin, J.M. (2012). Consistency of handedness, regardless of direction, predicts baseline memory accuracy and potential for memory enhancement. Journal of Experimental Psychology: Learning, Memory, and Cognition, 38, 187-193.

Lyle, K.B., \& Jacobs, N.E. (2010). Is saccade-induced retrieval enhancement a potential means of improving eyewitness evidence? Memory, 18, 581-594.

Lyle, K.B., Logan, J.M., \& Roediger, H.L., III. (2008). Eye movements enhance memory for individuals who are strongly right-handed and harm it for individuals who are not. Psychonomic Bulletin \& Review, 15, 515-520.

Lyle, K.B., McCabe, D.P., \& Roediger, H.L., III. (2008). Handedness is related to memory via hemispheric interaction: Evidence from paired associate recall and source memory tests. Neuropsychology, 22, 523-530.

Lyle, K.B., \& Orsborn, A.E. (2011). Inconsistent handedness and saccade execution benefit face memory without affect interhemispheric interaction. Memory, 19, 613-624. 
Oldfield, R.C. (1971). The assessment and analysis of handedness: the Edinburg inventory. Neuropsychologia, 9, 97-113.

Parker, A., \& Dagnall, N. (2010). Effects of handedness and saccadic bilateral eye movements on components of autobiographical recollection. Brain and Cognition, 73, 93-101.

Propper, R. E. \& Christman, S. (2004). Mixed- versus strong right-handedness is associated with biases toward 'remember' versus 'know' judgments in recognition memory: Role of interhemispheric interaction. Memory, 12, 707-714.

Propper, R.E., Christman, S.D., \& Phaneuf, K.A. (2005). A mixed-handed advantage in episodic memory: A possible role of interhemispheric interaction. Memory \& Cognition, 33, 751 757.

Witelson, S. F. (1985). The brain connection: The corpus callosum is larger in left-handers. Science, 229, 665-668. 


\section{Appendix A}

Actions performed without objects

1. Wave

2. Point to the monitor

3. Pat your head

4. Give a thumbs up

5. Knock on the desk

6. Blow a kiss

7. Snap your fingers

8. Count to five

9. Cover your eye

10. Squeeze your hand

Actions performed with objects

1. Pull out your chair

2. Drop a coin in the box

3. Move the mouse in a circle

4. Bounce the ball

5. Take a piece of tape

6. Roll the dice

7. Open the Tupperware

8. Use the hole puncher

9. Take off the marker cap

10. Flip over the card 
Table 1

Means of hand use

Hand use

Inconsistents

Consistents

Always left

.867

.822

Usually left

.933

.489

Equally left and right

1.267

,867

Usually right

1.200

1.000

Always right

1.367

1.267 